University of Wollongong

Research Online

Faculty of Engineering - Papers (Archive)

Faculty of Engineering and Information

Sciences

$1-1-2009$

\title{
Consolidation analysis of a stratified soil with vertical and horizontal drainage using the spectral method
}

Rohan Walker

Coffey Geotechnics Pty Ltd,, rtrwalker@gmail.com

Buddhima Indraratna

University of Wollongong, indra@uow.edu.au

Follow this and additional works at: https://ro.uow.edu.au/engpapers

Part of the Engineering Commons

https://ro.uow.edu.au/engpapers/845

\section{Recommended Citation}

Walker, Rohan and Indraratna, Buddhima: Consolidation analysis of a stratified soil with vertical and horizontal drainage using the spectral method 2009, 439-449.

https://ro.uow.edu.au/engpapers/845

Research Online is the open access institutional repository for the University of Wollongong. For further information contact the UOW Library: research-pubs@uow.edu.au 


\title{
Consolidation analysis of a stratified soil with vertical and horizontal drainage using the spectral method
}

\author{
R. WALKER* and B. INDRARATNA $\uparrow$
}

\begin{abstract}
A novel use of the spectral method to determine excess pore water pressure during vertical consolidation of multi-layered soil with time constant material properties is presented, considering a unit cell with combined vertical and radial drainage. Equal strain conditions are assumed in the analysis. The novel adoption of material properties that vary in a linear fashion with depth allows arbitrary distributions of properties to be modelled. By incorporating surcharge and vacuum loading that vary with both depth and time, a wide range of consolidation problems can be analysed. The spectral method is a meshless approach producing a series solution to the consolidation problem based on matrix operations. Accuracy can be improved by increasing the number of terms used in the series solution. The model is verified by the analysis of selected case studies characterised by: analytical free strain consolidation with thin sand layers (surcharge only); laboratory test and embankment trial with surcharge and vacuum loading; and ground subsidence caused by groundwater pumping.
\end{abstract}

KEYWORDS: clays; consolidation; drainage; soil stabilisation; theoretical analysis
La présente communication présente une nouvelle application de la méthode spectrale pour la détermination de la pression interstitielle excessive au cours de la consolidation verticale de terrains multicouches, avec propriétés de matériaux à constante de temps, en examinant une cellule unitaire à drainage mixte vertical et radial. Cette analyse présuppose l'existence de conditions à déformations égales. L'adoption innovante de propriétés de matériaux variant sur un plan linéaire en fonction de la profondeur permet de modéliser des distributions arbitraires de propriétés. En incorporant des surcharges et des charges sous vide variant en fonction de la profondeur et du temps, il est possible d'analyser une vaste gamme de problèmes de consolidation. La méthode spectrale est une approche sans maillage permettant de produire une solution en série au problème de la consolidation basé sur des opérations matricielles. Il est possible d'accroître la précision en augmentant le nombre de termes utilisés dans la solution en série. Le modèle est vérifié avec l'analyse de certaines études de cas caractérisées par : la consolidation analytique à déformation libre avec des couches de sable peu épaisses (surcharge seulement); des essais en laboratoire et test sur talus, avec surcharge et charge sous vide; et le tassement du sol causé par le pompage de la nappe phréatique.

\section{INTRODUCTION}

Soil is rarely homogeneous and to predict consolidation behaviour of a real soil successfully, heterogeneity must be modelled. By introducing multiple soil layers the analytical solution to consolidation problems is much more complicated compared with the relatively straightforward solutions available for single soil layers (Terzaghi, 1943; Barron, 1948; Yoshikuni \& Nakanodo, 1974; Hansbo, 1981, 2001; Tang \& Onitsuka, 2000; Zhu \& Yin, 2001; Han \& Ye, 2002; Leo 2004). The analytical solutions that have been developed for multi-layered soil consolidation consider flow in a cylindrical cell. The solutions, usually using the separation of variables technique, are quite lengthy and involve separate general equations for each soil layer whose unknown coefficients are determined from the zeros of a transcendental equation (i.e. eigenvalues) and the relationship between boundary, interface and initial conditions.

A number of solutions exist for two layer systems. Zhu \& Yin (2005) presented design charts for vertical drainage with two layers. Xie et al. (1999) solved the same problem with partially drained boundaries, while Xie et al. (2002) incorpo-

Manuscript received 14 March 2007; revised manuscript accepted 24 September 2008; published online ahead of print 11 February 2009. Discussion of this paper closes on 2 November 2009, for further details see $p$. ii.

* Coffey Geotechnics Pty. Limited, Sydney Australia \& Research Associate, School of Civil Engineering, Faculty of Engineering, University of Wollongong

$\dagger$ Faculty of Engineering, University of Wollongong, Wollongong City, NSW 2522, Australia rated small strain theory and non-linear soil properties where the decrease in permeability is proportional to the decrease in compressibility. Double layered ground with radial and vertical drainage was studied by Tang \& Onitsuka (2001) and Wang \& Jiao (2004). The two layer solutions can be used to study partially penetrating vertical drains. For more than two layers, Schiffman \& Stein (1970) presented equations for vertical drainage, and Horne (1964) presented equations including radial drainage. More recent work has developed newer techniques for modelling stratified soil. Chen et al. (2005) introduced the differential quadrature method to analyse one-dimensional (1D) consolidation of multiple soil layers. The differential quadrature method approximates the derivates in the continuity equation yielding a series of matrix equations to be solved. Nogami \& $\mathrm{Li}$ $(2002,2003)$ used the matrix transfer method in considering radial/horizontal and vertical flow in layered soil with thin sand layers, greatly simplifying the determination of eigenvalues in the vertical direction.

The above methods have some disadvantages, whether it be the restrictive geometry constraints of one and two layer solutions, the cumbersome implementation of multi-layered solutions or the limited loading choices of both. The current paper presents a new approach to solving multi-layered soil consolidation problems with greater ease than most of, and with far more versatility than all of, the existing methods mentioned above. Vertical and radial drainage is included as is combined surcharge and vacuum loading. The powerful spectral method (Boyd, 2000) is used to solve the governing equation, producing a single expression, calculated with common matrix operations, to give the pore pressure profile 
across all soil layers. The new model is verified against selected case histories.

\section{CONTINUITY EQUATION}

The derivation and solution of the governing partial differential equation for consolidation with vertical and radial drainage, including depth dependent soil properties can be found, in full, in Walker (2006). The derivation is summarised below. Fig. 1 shows a unit cell of height $H$, and external radius $r_{\mathrm{e}}$. The radius of the vertical drain and smear zone are $r_{\mathrm{w}}$ and $r_{\mathrm{s}}$, respectively. Horizontal permeability in the smear and undisturbed zone are respectively $k_{\mathrm{h}}^{\prime}$ and $k_{\mathrm{h}}$. The excess pore water pressure in the drain is designated $w$ and will be negative for vacuum loading. Drainage conditions in the vertical direction are either, pervious top and pervious bottom (PTPB), or pervious top and impervious bottom (PTIB). $k_{\mathrm{v}}$ is the vertical permeability $\left(k_{\mathrm{v}}\right.$ in smear and undisturbed zone assumed equal). Soil properties vary in a piecewise linear fashion with depth. Hansbo (1981) provides equal strain consolidation equations considering radial flow only. In order to include flow in the vertical direction it is assumed, as per Tang \& Onitsuka (2000) and Wang \& Jiao (2004), that flow is governed by the average vertical excess pore pressure gradient. That is, the excess pore pressure is averaged in the radial direction and it is the vertical gradient of this average value that determines the flow vertically. With the above treatment of vertical drainage the derivation of Hansbo (1981) can be modified to give the average pore water pressure at normalised depth $Z$ (equal to $z / H)$

$$
\begin{aligned}
\frac{m_{\mathrm{v}}}{\bar{m}_{\mathrm{v}}} \frac{\partial \bar{u}}{\partial t}= & -\left[\mathrm{d} T_{\mathrm{h}} \frac{\eta}{\bar{\eta}} \bar{u}-\mathrm{d} T_{\mathrm{v}}\left(\frac{\partial}{\partial Z}\left(\frac{k_{\mathrm{v}}}{\bar{k}_{\mathrm{v}}}\right) \frac{\partial \bar{u}}{\partial Z}+\frac{k_{\mathrm{v}}}{\bar{k}_{\mathrm{v}}} \frac{\partial^{2} \bar{u}}{\partial Z^{2}}\right)\right] \\
& +\frac{m_{\mathrm{v}}}{\bar{m}_{\mathrm{v}}} \frac{\partial \bar{\sigma}}{\partial t}+\mathrm{d} T_{\mathrm{h}} \frac{\eta}{\bar{\eta}} w
\end{aligned}
$$

where

$$
\begin{aligned}
& \mathrm{d} T_{\mathrm{v}}=\frac{\bar{c}_{\mathrm{v}}}{H^{2}} \\
& \mathrm{~d} T_{\mathrm{h}}=\frac{2 \bar{\eta}}{\gamma_{\mathrm{w}} \bar{m}_{\mathrm{v}}} \\
& \eta=\frac{k_{\mathrm{h}}}{r_{\mathrm{e}}^{2} \mu}
\end{aligned}
$$

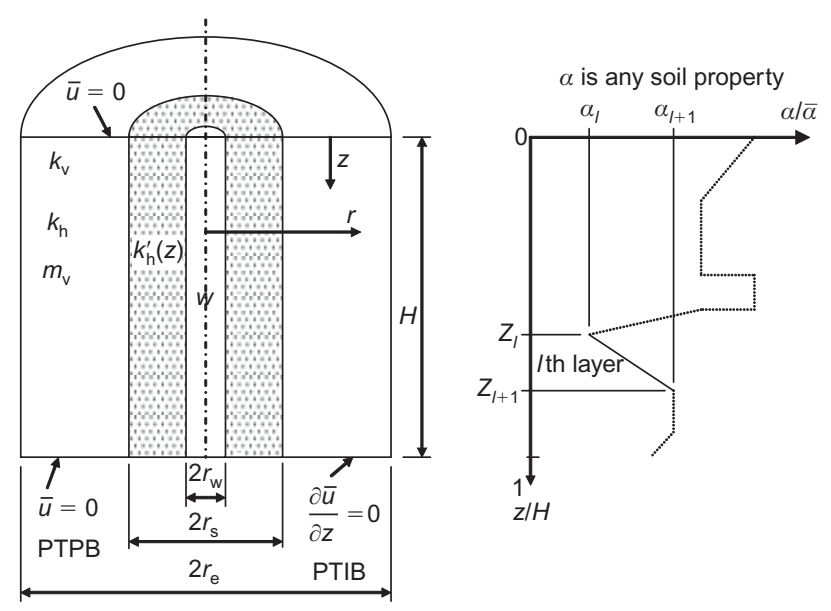

Fig. 1. Unit cell

$$
\bar{c}_{\mathrm{V}}=\frac{\bar{k}_{\mathrm{v}}}{\gamma_{\mathrm{w}} \bar{m}_{\mathrm{v}}}
$$

$\bar{u}=$ excess pore water pressure at a particular depth, $\gamma_{w}=$ unit weight of water, $m_{\mathrm{v}}=$ coefficient of volume compressibility ( $m_{\mathrm{v}}$ in smear and undisturbed zone assumed equal), $\bar{\sigma}$ $=$ average total stress. The $\mu$ parameter depends on the smear zone and radial geometry of the problem. $\mu$ parameters for various smear zone configurations (including plane strain cases) can be found in Hansbo (1981), Walker \& Indraratna (2006), Walker \& Indraratna (2007), Hird et al. (1992), Indraratna \& Redana (1997). $\bar{k}_{\mathrm{v}}, \bar{m}_{\mathrm{v}}$ and $\bar{\eta}$ are convenient reference values for the relevant parameters. Pertinent points regarding equation (1) and these reference values are discussed below.

\section{Depth and time dependence of parameters}

The soil properties $m_{\mathrm{v}}, k_{\mathrm{v}}$, and $\eta$ are all assumed to vary with depth (independent of time), in a piecewise linear fashion (Fig. 1) (note that parameters in equation (1) are not written explicitly as $k_{\mathrm{v}}(Z)$ etc.). Using a linear variation of material properties is very useful when modelling arbitrary property distributions. For multi-layer consolidation models with constant material properties within a soil layer, modelling a large change in a particular parameter over a short distance involves subdividing a region into many thin layers. With a linear variation of properties, the approximation of the property distribution can be accomplished with far fewer layers. The surcharge and vacuum loading parameters, $\bar{\sigma}$ and $w$, are assumed to vary with both depth and time in a piecewise linear fashion. The explicit treatment of linearly varying loads is better than many numerical approaches where varying loads are discretised into a number of constant step loads.

\section{Treatment of $\eta$}

The lumped parameter, $\eta$, is linked to the contribution of horizontal drainage. To prevent horizontal drainage within a particular soil layer $\eta$ is set equal to zero. This is useful for analysing problems with partially penetrating vertical drains. Soil layers below the penetration depth will have $\eta=0$ while still allowing vertical drainage. Other than purely numerical methods, existing solutions for partially penetrating drains are only available for two layer systems. The present method can also predict the effect of using both long and short drains in unison. In the lower soil layers where only the longer drains occur, $\eta$ will be less than in the upper layers where both long and short vertical drains provide drainage. The treatment of $\eta$ greatly increases the versatility of the model. $\eta$ is considered to vary linearly with depth rather than its component parts $\left(r_{\mathrm{e}}, \mu\right.$ and $\left.r_{\mathrm{e}}\right)$ primarily to avoid the mathematical complications of having linear polynomials in the denominator of expressions.

\section{Normalisation of parameters}

Parameters in equation (1) have been normalised with respect to certain reference values. Depth $z$ has been normalised to the total depth of the entire soil profile $H$ regardless of the drainage conditions. For pervious top and pervious bottom drainage conditions one might expect to consider half the entire soil depth as a normalisation value (such as Terzaghi, 1943). When non-uniform property and loading variations are considered, however, the 'boundary' separating upwards and downwards flow does not fall in the centre of the soil profile and may move during consolidation such that taking half the soil depth as the drainage path is invalid. 
The properties $k_{\mathrm{v}}, m_{\mathrm{v}}$ and $\eta$ are referenced to any convenient value, such as the values in the first soil layer. The normalisation process yields the two parameters $\mathrm{d} T_{\mathrm{v}}$ and $\mathrm{d} T_{\mathrm{h}}$ which are analogous to Terzaghi's vertical time factor, and the exponential term in Hansbo's radial consolidation equations. In can indeed be seen that, for homogeneous soil properties, if radial terms are ignored then equation (1) reduces to Terzaghi 1D consolidation. If vertical terms in equation (1) are ignored then Hansbo's (1981) radial consolidation equation is produced. Normalising the soil properties reveals that it is the relative values of parameters across layers that govern the consolidation process and any deviations from the classic 1D consolidation equations. Another advantage of considering normalised parameters is that it is generally easier to assess the relative magnitudes of a particular soil property than the absolute magnitudes. Thus when predicting or back-analysing consolidation problems, relative values of $k_{\mathrm{v}}, m_{\mathrm{v}}$ and $\eta$ might be determined with some certainty after which $\mathrm{d} T_{\mathrm{v}}$ and $\mathrm{d} T_{\mathrm{h}}$ can be varied to either give a sensitivity analysis or fit the measured data.

\section{Limitations}

The unit-cell approach adopted in this paper assumes that deformation occurs in the vertical direction only and that such strains do not vary in the radial direction (equal strain). Stresses and strains associated with shearing and variations in vertical and lateral settlement that are expected with two(2D) or three-dimensional (3D) problems are not accounted for. The model will thus give best results when analysing problems where 1D deformation is expected (e.g. under the centreline of an embankment) and horizontal drainage paths are short (e.g. in vertical drain problems). Away from embankment centrelines the model can still give approximate answers owing to the ability to model the strongly depth-dependent loading expected in such areas. The soil and geometry do not change with time so the model is only valid for small strains. Reasonable results are obtained, however, if average soil properties over the consolidation period are used as shown in the two field case studies shown below. If time or stress dependence of properties must be considered then equation (1) can be solved numerically, which is relatively easy to do (compared with $2 \mathrm{D}$ and $3 \mathrm{D}$ equations) owing to the $1 \mathrm{D}$ nature of the equation.

\section{SOLUTION OF GOVERNING EQUATION WITH THE SPECTRAL METHOD}

Equation (1) is a non-homogeneous partial differential equation with source/sink terms. The source/sink terms are functions of depth and time and arise from surcharge and vacuum loading. Following Duhamel's principle (Asmar, 2004) equation (1) is solved for an impulse load to obtain a 'fundamental solution'. The general solution is then found by integrating the fundamental solution across the entire problem space using the actual loading terms. The solution of equation (1) by the spectral method (Boyd, 2000) is summarised below.

The spectral method involves expressing the excess pore pressure distribution $\bar{u}(Z, t)$ as a truncated series of $N$ terms

$$
\bar{u}(Z, t) \approx \Phi \mathbf{A}
$$

where

$$
\begin{aligned}
& \Phi=\left[\begin{array}{llll}
\phi_{1}(Z) & \phi_{2}(Z) & \ldots & \phi_{N}(Z)
\end{array}\right] \\
& \mathbf{A}^{T}=\left[\begin{array}{llll}
A_{1}(t) & A_{2}(t) & \ldots & A_{N}(t)
\end{array}\right]
\end{aligned}
$$

In the preceding, $\phi_{j}(Z)$ is a set of linearly independent basis functions, and $A_{j}(t)$ are unknown coefficients. The basis functions are chosen to satisfy the boundary conditions. In the current analysis, for PTPB $\bar{u}(0, t)=0$ and $\bar{u}(H, t)=0$, and for PTIB $\bar{u}(0, t)=0$ and $\partial \bar{u}(H, t) / \partial z=0$. Suitable basis functions are thus

$$
\phi_{j}(Z)=\sin \left(M_{j} Z\right)
$$

where

$$
M_{j}=\left\{\begin{array}{cc}
j \pi & \text { PTPB } \\
\frac{\pi}{2}(2 j-1) & \text { PTIB }
\end{array}\right.
$$

Considering orthogonality of the basis functions it is found that

$$
\int_{0}^{1} \phi_{i} L(\mathbf{\Phi} \mathbf{A}) \mathrm{d} Z-\int_{0}^{1} \phi_{i} f(Z, t) \mathrm{d} Z=0, \text { for } i=1, \ldots, N
$$

where, $L$ is an operator involving partial derivatives associated with equation (1). Substituting equation (6) and its derivatives along with equation (6) into equation (10) yields a set of coupled ordinary differential equations for $A_{j}(t)$. The integrations of equation (10) are performed across all soil layers in a piecewise fashion (the explicit terms that arise from equation (10) are described in the Appendix). When step changes in soil properties occur an interface layer is introduced. The contribution of an interface layer can be found by taking the limit as layer thickness which reduces to zero in the equations for layers of finite thickness (equations (20) and (22) in the Appendix). It is this treatment of layer interfaces that provides a large advantage over traditional approaches. In previous methods, the addition of a new layer required the inclusion of a new domain in the problem space. For each new domain introduced, additional equations for pore pressure with associated unknown coefficients are needed. When many layers are analysed, the number of unknown coefficients to solve for can become unwieldy. In the current method, the number of unknown coefficients to solve for, $A_{j}(t)$ in equation (6), is fixed at the start of the analysis, regardless of the number of layers used.

In solving equation (10) the distribution of material properties, $k_{\mathrm{v}}, m_{\mathrm{v}}$ and $\eta$ contributes to a square matrix $\Gamma^{-1} \Psi$ (see the Appendix). The most difficult part of the analysis is calculating the eigenvalues and eigenvectors of this matrix. There is, however, a comprehensive literature on eigenvalue problems (Hoffman, 1992) and many software programs exist to solve them. Eigenvalue problems can be easily solved with freeware subroutines for Visual Basic for Applications (Volpi, 2005) and FORTRAN (Anderson et al. 1999). Eigenvalues are also used when using previous solution methods to consolidation problems. These eigenvalues are typically the roots of a non-standard transcendental equation. Determining the equation roots can be more difficult than performing the well-known operations of matrix eigenvector and eigenvalue extraction used in the current method. Particular advantage is gained when some existing methods suggest finding roots by plotting the transcendental equation and determining the roots visually (Nogami \& Li, 2003).

The system of equations arising from equation (10) can be solved for the fundamental solution from which the general solution becomes

$$
\begin{aligned}
\bar{u}(Z, t)= & \int_{0}^{t} \int_{0}^{1} \Phi \mathbf{v E}(t-\tau)(\Gamma \mathbf{v})^{-1} \Phi(\zeta)^{T} \\
& \times\left(\frac{m_{\mathrm{v}}}{\bar{m}_{\mathrm{v}}} \frac{\partial \bar{\sigma}}{\partial t}+\mathrm{d} T_{\mathrm{h}} \frac{\eta}{\bar{\eta}} w\right) \mathrm{d} \zeta \mathrm{d} \tau
\end{aligned}
$$


where, the individual matrix terms are defined in the Appendix. Equation (11) is valid for any depth and time variation of $\bar{\sigma}$ and $w$. Using the linear variation of loading and properties assumed above, the final solution of equation (1) is found to be

$$
\bar{u}(Z, t)=\Phi \mathbf{v}(\boldsymbol{\sigma}+\mathbf{w})
$$

There is considerable advantage in having the entire pore pressure distribution across all soil layers defined by a single equation, i.e. equation (12). All previous methods involve separate equations to describe the pore water pressure in each soil layer. Such equations typically involve combinations of sine and cosine terms, and Bessel functions for freestrain radial drainage conditions (Horne, 1964; Nogami \& $\mathrm{Li}$, 2003). Thus finding average pore pressure values by integrating across multiple layers is tedious. Using the current method it is equally straightforward to determine average pore pressure (equation (33)) values within a soil layer, across some layers, or across all layers. Equations (12) and (33) are very concise, showing that soil consolidation can be reduced to a series of matrix operations.

Care should be taken when including vacuum loading, because owing to the formulation, pore pressure will always be zero at $Z=0$. Thus vacuum loading is applied only along the drain and not across the soil surface. The mathematical problem arises where, if vertical flow is allowed and vacuum is applied along the drain, pore water will flow from the $\bar{u}=0$ boundary condition at $Z=0$ into the soil (with negative pore pressure) and then into the drain. This restriction can be overcome by using a thin layer with high horizontal permeability at the soil surface. The mathematical problem will still exist, but the unwanted flow into the soil will quickly flow into the drain and not affect the pore pressure at the bottom of the thin layer. The pore pressure at the bottom of the thin layer will approach that of the applied vacuum as required.

\section{LI, 2003)",5,1,0,0,1pc,1pc,0pc,0pc>COMPARISON WITH MULTI-LAYERED FREE-STRAIN APPROACH (NOGAMI \& LI, 2003)}

Nogami \& Li (2003) developed a free-strain approach for calculating the excess pore pressure distribution for multilayered soil with both vertical and radial drainage. An example problem is presented with a soil system consisting of two identical thin sand layers (height $h_{\mathrm{s}}$ ) separating three identical clay layers (height $h_{\mathrm{c}}$ ). Soil properties are described by the ratios: $k_{\text {sand }} h_{\mathrm{s}} h_{\mathrm{c}} / r_{\mathrm{e}}^{2} k_{\mathrm{v}}=5, \quad n=20$, $c_{\mathrm{h}} h_{\mathrm{c}}^{2} / c_{\mathrm{v}} r_{\mathrm{e}}^{2}=1$. The average excess pore water pressure calculated with the present approach and that of Nogami \& Li (2003) is compared in Fig. 2 (20 series terms are used). Both methods are in close agreement except for slight deviations in the thin sand layers at a low degree of consolidation. The close agreement shows that, as for homogenous ground (Hansbo, 1981; Barron, 1948), there is little difference between free-strain and equal-strain formulations. The current method does not use cumbersome Bessel functions that are associated with free-strain solutions. Also a wider range of problems can be solved with the current method, as the approach of Nogami \& Li (2003) does not include vacuum loading or depth-dependent surcharge loading.

\section{VERTICAL DRAINAGE IN A SINGLE LAYER WITH CONSTANT $c_{\mathrm{V}}$}

By relaxing the assumption of soil homogeneity, the proposed model can be used to investigate some deviations from Terzaghi's 1D consolidation theory. Consider a single

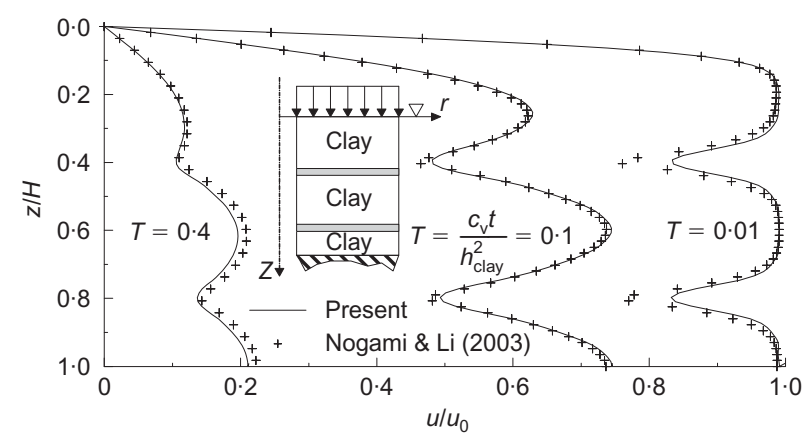

Fig. 2. Pore pressure distribution: equal-strain plotted against free-strain

layer of soil where $k_{\mathrm{v}}$ and $m_{\mathrm{v}}$ vary linearly with depth such that $c_{\mathrm{V}}$ remains constant throughout the soil. This restriction is ensured when $k_{\mathrm{vT}} / k_{\mathrm{vB}}=m_{\mathrm{vT}} / m_{\mathrm{vB}}$, where the subscripts $\mathrm{T}$ and $\mathrm{B}$ indicate the top and bottom of the soil layer, respectively. The effect of the $k_{\mathrm{vT}} / k_{\mathrm{vB}}$ ratio on consolidation is assessed by calculating the average degree of consolidation for PTIB and PTPB drainage conditions, under uniform and triangular initial pressure distributions. Consolidation curves are shown in Fig. 3 and Fig. 4 (20 series terms are used). The curves for two-way drainage (PTPB), regardless of initial pressure distribution, are very similar so only the case of uniform initial pressure distribution is shown.

As $k_{\mathrm{v}}$ and $m_{\mathrm{v}}$ generally decrease with increasing effective stress, it is expected that $k_{\mathrm{vT}} / k_{\mathrm{vB}}>1$ for most soils. As seen from Fig. 3 such cases exhibit a faster rate of consolidation compared with Terzaghi's theory $\left(k_{\mathrm{vT}} / k_{\mathrm{vB}}=1\right)$. This is consistent with higher strains (higher $m_{\mathrm{v}}$ ) near the drainage boundary causing faster consolidation as described by Duncan (1993). Fig. 3(c) shows an initially slower consolidation rate eventually 'overtaking' the Terzaghi rate. This somewhat surprising result is caused by the inverted triangle pressure distribution: for $k_{\mathrm{vT}} / k_{\mathrm{vB}}>1$ there is initially greater flow downwards towards the impermeable boundary (see Fig. 3(c)). The rate of consolidation for twoway drainage is only marginally affected by the $k_{\mathrm{vT}} / k_{\mathrm{vB}}$ ratio (Fig. 4). Once $k_{\mathrm{vT}} / k_{\mathrm{vB}}>2$, however, any change in linear distribution of $k_{\mathrm{v}}$ and $m_{\mathrm{v}}$ will give a slight decrease in consolidation rate. Note that in Fig. 4, owing to symmetry the case $k_{\mathrm{vT}} / k_{\mathrm{vB}}=20$ is the same as $k_{\mathrm{vT}} / k_{\mathrm{vB}}=1 / 20$.

The above findings are significant for thick clays with PTIB drainage conditions. A change in $k_{\mathrm{vT}} / k_{\mathrm{vB}}=m_{\mathrm{vT}} / m_{\mathrm{vB}}$ may lead to significant changes in the rate of consolidation. As, however, $k_{\mathrm{vT}} / k_{\mathrm{vB}}>1$ leads ultimately to faster consolidation, and is expected in the field, using Terzaghi's analysis $\left(k_{\mathrm{vT}} / k_{\mathrm{vB}}=1\right)$ will simply underestimate the rate of consolidation (a generally safe design approach). The rate of consolidation will also be underestimated when determining consolidation times by comparing the time factors $\left(T_{\mathrm{v}}=c_{\mathrm{v}} t / H^{2}\right)$ of two similar soils with different drainage lengths (sometimes called the model law of consolidation (Craig, 1997)). Terzaghi's theory depends only on the time factor. The above analysis shows that consolidation depends also on the parameter $k_{\mathrm{vT}} / k_{\mathrm{vB}}=m_{\mathrm{vT}} / m_{\mathrm{vB}}$. Thus, comparing the time factors, the rate of consolidation for a thin sample such as an oedometer specimen, where $k_{\mathrm{vT}} / k_{\mathrm{vB}} \approx 1$, will be different to a thicker specimen such as in the field, where $k_{\mathrm{vT}} / k_{\mathrm{vB}} \neq 1$. 


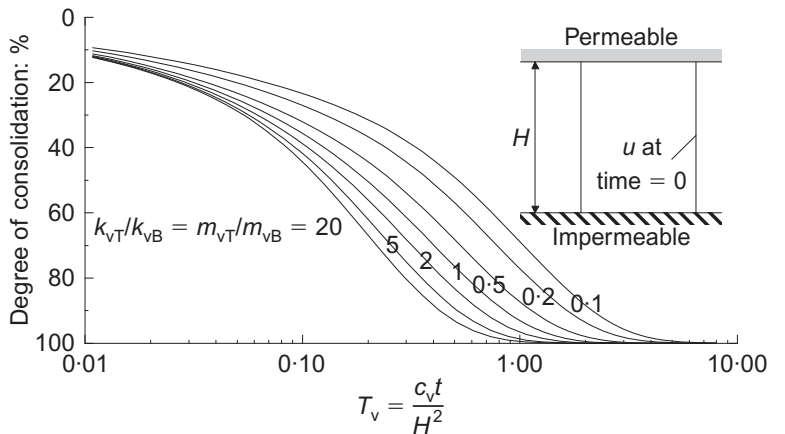

(a)

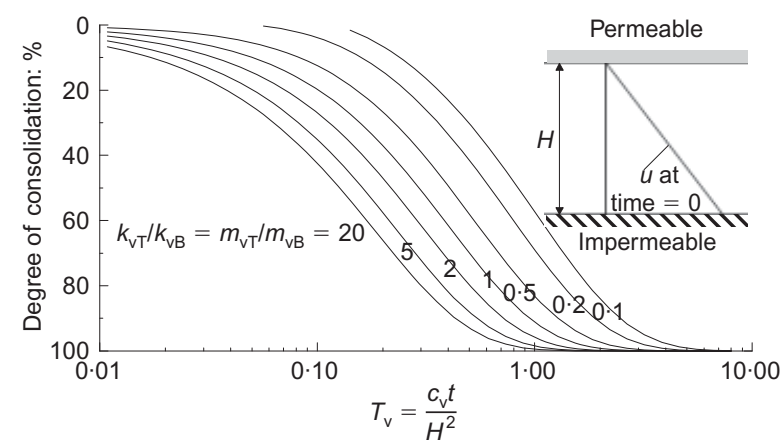

(b)

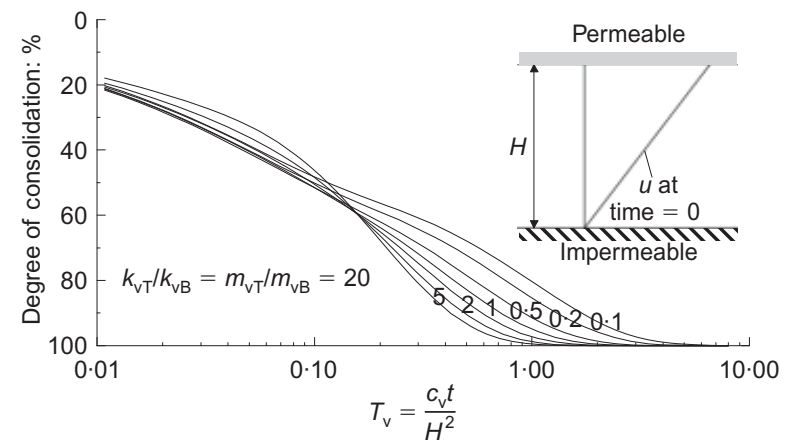

(c)

Fig. 3. Degree of consolidation for pervious top and impervious bottom (PTIB) condition

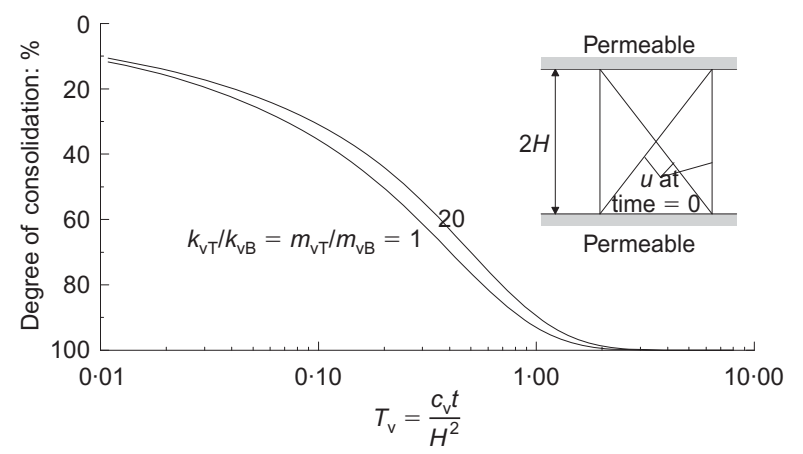

Fig. 4. Degree of consolidation for pervious top and pervious bottom (PTPB) condition

\section{COMPARISON WITH SELECTED CASE HISTORIES \\ Modelling of large-scale consolidation cell}

Soil properties, testing procedures, settlement and pore pressure data for the laboratory test described below are described fully in Indraratna et al. (2004), Indraratna \& Redana (1998a) and Indraratna \& Redana (1998b). The relevant data (summarised below) from this test are reanalysed here with the proposed consolidation equations. Predicted and measured settlement data are compared.
Reconstituted alluvial clay from Moruya (40 to 50\% clay sized particles $(<2 \mu \mathrm{m})$, saturated water content $=40 \%$, liquid limit $=70 \%$, plastic limit $=30 \%$, saturated unit weight $=18 \cdot 1 \mathrm{kN} / \mathrm{m}^{3}$ ) was thoroughly mixed and placed in the steel consolidation cell, which is a stainless steel cylinder (height $=950 \mathrm{~mm}$, diameter $=450 \mathrm{~mm}$ ), where drainage is provided at the top of the soil. The height of the sample can be shortened by using an internal 'riser'. The ring friction expected with a large height/diameter ratio (1.5-2) is almost eliminated by using an ultra-smooth Teflon membrane around the cell boundary (friction coefficient less than $0 \cdot 03)$. The soil was subjected to an initial preconsolidation pressure, $\sigma_{\mathrm{p}}^{\prime}=20 \mathrm{kPa}$ until the settlement rate became negligible. The load was then removed and a single prefabricated vertical drain (PVD) $(100 \mathrm{~mm} \times 3 \mathrm{~mm})$ was installed using a rectangular steel mandrel. After drain installation, a $-100 \mathrm{kPa}$ vacuum was applied at the top of the cell and the surcharge pressure was increased in two stages to $50 \mathrm{kPa}$ and $100 \mathrm{kPa}$. The vacuum pressure was subsequently removed and reapplied. Pore pressure measurements indicate that the vacuum pressure along the drain decreases approximately linearly with depth to $-70 \mathrm{kPa}$ at the bottom of the cell.

The measured soil properties are as follows: compression index $C_{\mathrm{c}}=0 \cdot 34$, recompression index $C_{\mathrm{r}}=0 \cdot 12$, vertical coefficient of permeability $k_{\mathrm{v}}=1.1 \times 10^{-10} \mathrm{~m} / \mathrm{s}$, and undisturbed horizontal permeability $k_{\mathrm{h}}=2.5 \times 10^{-10} \mathrm{~m} / \mathrm{s}$. The equivalent radius of the band drain (after Rixner et al., $1986)$ is $r_{\mathrm{w}}=(100+3) / 4=26 \mathrm{~mm}$. The extent of smear zone is a function of soil disturbance surrounding the PVD, and is dependent on the ratio of $k_{\mathrm{h}}$ inside the smear zone to the undisturbed value of $k_{\mathrm{v}}$. For instance, outside the smear zone the $k_{\mathrm{h}} / k_{\mathrm{v}}$ ratio may be $3-4$, but within the smear zone this ratio drops significantly to values approaching unity in the near vicinity of the drain location where the mandrel has totally remoulded the soil (Indraratna \& Redana, 2000, Sathananthan \& Indraratna, 2006). The radius of smear zone was assumed to be four times the equivalent drain radius, with a constant horizontal permeability equal to the vertical permeability (Indraratna \& Redana, 1998a). Given the above parameters, $\mu=3.06$ and the vertical and horizontal coefficients of consolidation are taken as $c_{\mathrm{v}}=5.7 \times 10^{-9}$ $\mathrm{m}^{2} / \mathrm{s}$ and $c_{\mathrm{h}}=13.2 \times 10^{-9} \mathrm{~m}^{2} / \mathrm{s}$.

Average excess pore pressure for the whole soil mass was calculated using equation (33). For an initial void ratio of $e_{0}=1 \cdot 1$, the settlement, $\rho$, was then calculated using

$$
\rho= \begin{cases}\frac{H C_{\mathrm{r}}}{1+e_{0}} \log \left(\frac{\sigma^{\prime}}{\sigma_{0}^{\prime}}\right) & \sigma^{\prime}<\sigma_{\mathrm{p}}^{\prime} \\ \frac{H C_{\mathrm{r}}}{1+e_{0}} \log \left(\frac{\sigma_{\mathrm{p}}^{\prime}}{\sigma_{0}^{\prime}}\right)+\frac{H C_{\mathrm{c}}}{1+e_{0}} \log \left(\frac{\sigma^{\prime}}{\sigma_{\mathrm{p}}^{\prime}}\right) & \sigma^{\prime}>\sigma_{\mathrm{p}}^{\prime}\end{cases}
$$

The calculated and measured settlements are shown in Fig. 5 (20 series terms are used). The settlements calculated show an appropriate response to vacuum removal and reloading illustrating the applicability of the proposed consolidations equations in modelling such phenomena.

\section{Second Bangkok International Airport}

As part of the Second Bangkok International Airport (30 km east of Bangkok, Thailand) a series of test embankments was constructed to assess the behaviour of the thick compressible subsoil. The surface settlements at the middle of two embankments, TV1 and TV2, incorporating vacuum loading and vertical drains are analysed here. Both embankments have previously been analysed using the finite element 


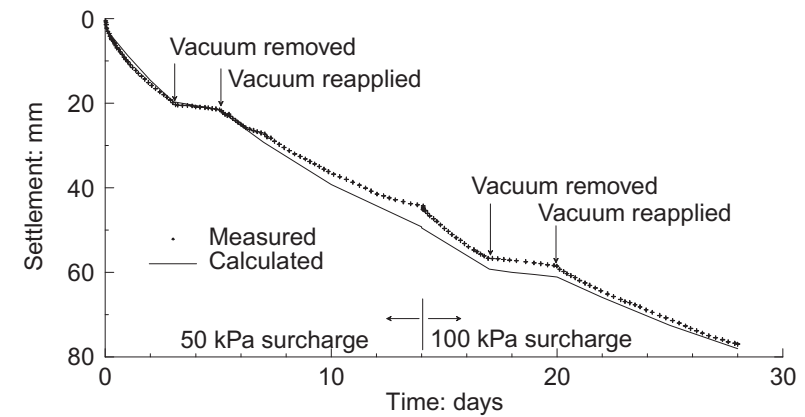

Fig. 5. Settlement of large-scale consolidation cell

method (Bergado et al., 1998; Indraratna et al., 2004; Indraratna et al., 2005).

The subsoil can be divided into five sublayers: weathered clay $(0-2 \mathrm{~m})$, very soft clay $(2-8.5 \mathrm{~m})$, soft clay $(8 \cdot 5-$ $10.5 \mathrm{~m})$, medium clay $(10.5-13 \mathrm{~m})$ and stiff to hard clay $(13-15 \mathrm{~m})$. The Cam-clay properties of each layer used in previous finite element analyses are given in Table 1. Each embankment covers an area of $40 \mathrm{~m} \times 40 \mathrm{~m}$. For TV1, PVD ( $r_{\mathrm{w}}=0.05 \mathrm{~m}, 15 \mathrm{~m}$ long at $1 \mathrm{~m}$ triangular spacing) were installed from a working platform comprising $0.3 \mathrm{~m}$ of sand. Drainage at the surface was provided by a hypernet drainage system. To facilitate vacuum application, a geomembrane liner was placed above the drainage layer and sealed by a bentonite trench surrounding the embankment. A $-60 \mathrm{kPa}$ vacuum was applied and the embankment height was subsequently raised in stages to a height of $2.5 \mathrm{~m}$ (the unit weight of surcharge fill was $18 \mathrm{kN} / \mathrm{m}^{3}$ ). TV2 was similarly constructed but with a $0 \cdot 8 \mathrm{~m}$ working platform, $12 \mathrm{~m}$ long PVD, and a drainage system of geotextiles and perforated pipes.

To model the effects of PVD, a smear zone with radius six times the effective drain radius was assumed, resulting in $r_{\mathrm{s}}=0.3 \mathrm{~m}$ and a $\mu$ value of approximately 3.95 for all layers. The properties at the top of the very soft clay were used as reference values with $\bar{c}_{\mathrm{v}}=0.005 \mathrm{~m}^{2} /$ day,

Table 1. Soil parameters for SBIA test embankments

\begin{tabular}{l|c|c|c|c|c|c|c}
\hline Depth: $\mathrm{m}$ & $\lambda$ & $\kappa$ & $v$ & $e_{0}$ & $\begin{array}{c}\gamma: \\
\mathrm{kN} / \mathrm{m}^{3}\end{array}$ & $\begin{array}{c}k_{\mathrm{v}}: \\
10^{-9} \mathrm{~m} / \mathrm{s}\end{array}$ & $\begin{array}{c}k_{\mathrm{h}}: \\
10^{-9} \mathrm{~m} / \mathrm{s}\end{array}$ \\
\hline $0-2$ & $0 \cdot 3$ & $0 \cdot 03$ & $0 \cdot 3$ & $1 \cdot 8$ & 16 & $15 \cdot 1$ & $30 \cdot 1$ \\
$2-8 \cdot 5$ & $0 \cdot 7$ & $0 \cdot 08$ & $0 \cdot 3$ & $2 \cdot 8$ & 15 & $6 \cdot 4$ & $12 \cdot 7$ \\
$8 \cdot 5-10 \cdot 5$ & $0 \cdot 5$ & $0 \cdot 05$ & $0 \cdot 25$ & $2 \cdot 4$ & 15 & $3 \cdot 0$ & $6 \cdot 0$ \\
$10 \cdot 5-13$ & $0 \cdot 3$ & $0 \cdot 03$ & $0 \cdot 25$ & $1 \cdot 8$ & 16 & $1 \cdot 3$ & $2 \cdot 6$ \\
$13-15$ & $0 \cdot 1$ & $0 \cdot 01$ & $0 \cdot 25$ & $1 \cdot 2$ & 18 & $0 \cdot 3$ & $0 \cdot 6$ \\
\hline
\end{tabular}

Table 2. Layer properties for modelling of SBIA test embankments

\begin{tabular}{l|c|c|c}
\hline Depth: $\mathrm{m}$ & $k_{\mathrm{v}} / \bar{k}_{\mathrm{v}}$ & $\eta / \bar{\eta}$ & $m_{\mathrm{v}} / \bar{m}_{\mathrm{v}}$ \\
\hline 0 & $2 \cdot 36$ & $2 \cdot 36$ & $0 \cdot 37$ \\
2 & $2 \cdot 36$ & $2 \cdot 36$ & $0 \cdot 41$ \\
2 & $1 \cdot 00$ & $1 \cdot 00$ & $1 \cdot 00$ \\
$8 \cdot 5$ & $1 \cdot 00$ & $1 \cdot 00$ & $0 \cdot 49$ \\
$8 \cdot 5$ & $0 \cdot 47$ & $0 \cdot 47$ & $0 \cdot 34$ \\
$10 \cdot 5$ & $0 \cdot 47$ & $0 \cdot 47$ & $0 \cdot 59$ \\
$10 \cdot 5$ & $0 \cdot 20$ & $0 \cdot 20$ & $0 \cdot 35$ \\
13 & $0 \cdot 20$ & $0 \cdot 20$ & $0 \cdot 25$ \\
13 & $0 \cdot 05$ & $0 \cdot 05$ & $0 \cdot 08$ \\
15 & $0 \cdot 05$ & $0 \cdot 05$ & $0 \cdot 09$ \\
\hline
\end{tabular}

$\bar{c}_{\mathrm{h}}=0.01 \mathrm{~m}^{2} /$ day and $\bar{\eta}=0.02$. The relevant parameters for the other layers used in the analysis are shown in Table 2. In calculating the $k_{\mathrm{v}} / \bar{k}_{\mathrm{v}}$ parameter the permeability coefficients in each layer, are taken from Table 1 . As the vertical drain configuration and smear zone properties are assumed to be identical in each layer, the relative value of the vertical drain parameter $\eta / \bar{\eta}$ will depend only on the permeability values, and thus have the same value as the $k_{\mathrm{v}} / \bar{k}_{\mathrm{v}}$ parameter. The compressibility parameter $m_{\mathrm{v}} / \bar{m}_{\mathrm{v}}$ chosen is based on the void ratio change expected from an effective stress increase of $50 \mathrm{kPa}$ using the Cam-clay compressibility properties in Table 1). The initial effective stress and overconsolidation ratio required for such a void ratio change calculation are interpolated from Fig. 6. For TV2, the displacement of soil below a depth of $12 \mathrm{~m}$ was ignored (i.e. non-displacement boundary).

To calculate surface settlements, the excess pore pressure at 30 equally spaced points (see Walker (2006) for full details) in the soil system was calculated using the proposed consolidation equations (equation (12)). The compression of each of these sublayers was calculated by equation (13) and then summed to give the total surface settlement with time. The calculated and measured surface settlements for the two embankments, along with the surcharge and assumed vacuum loading stages, are shown in Fig. 7 (43 series terms are used). Piezometer readings indicate that the constant total vacuum pressure applied by the vacuum pump does not fully transfer to the soil, hence the assumed vacuum variation over time in Fig. 7. Loss of vacuum may be caused by air leaks in the system. Also Indraratna et al. (2005) suggest that the vacuum pressure can vary linearly with depth within the PVD. In this analysis, the vacuum pressure was assumed to vary from the value given in Fig. 7 at the soil surface, to zero at the bottom of the drain.

The calculated surface settlements are in close agreement with the measured values verifying that the proposed model can be used to analyse multi-layer problems with complex

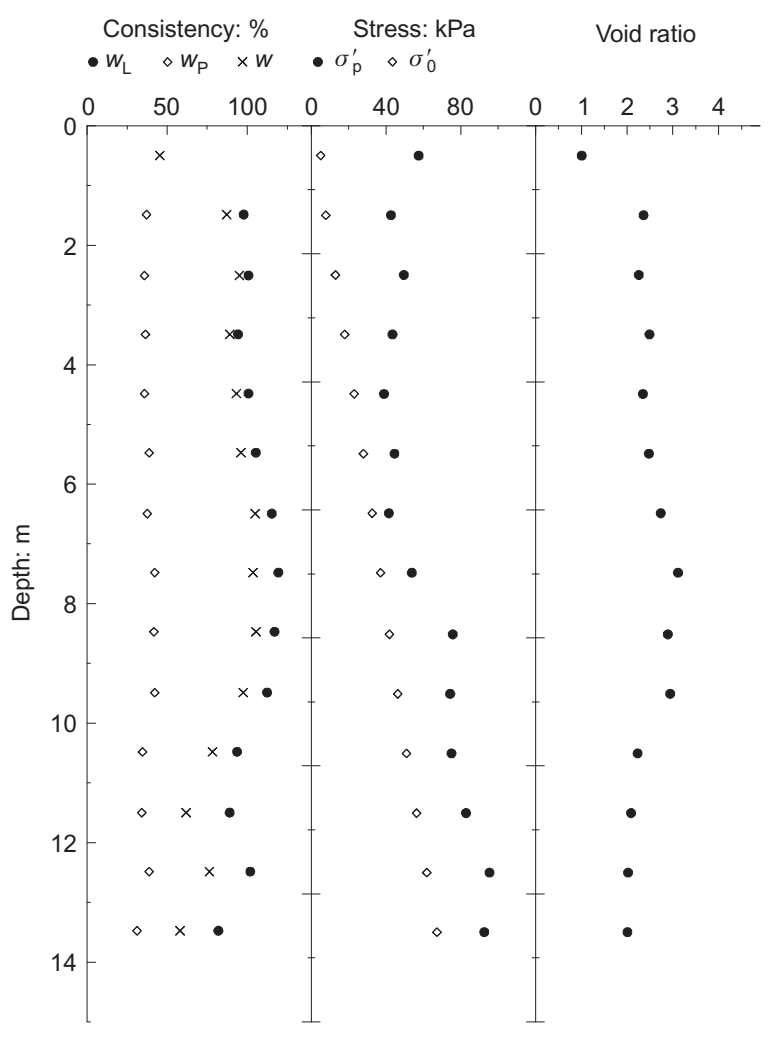

Fig. 6. Soil properties for the SBIA test embankments 


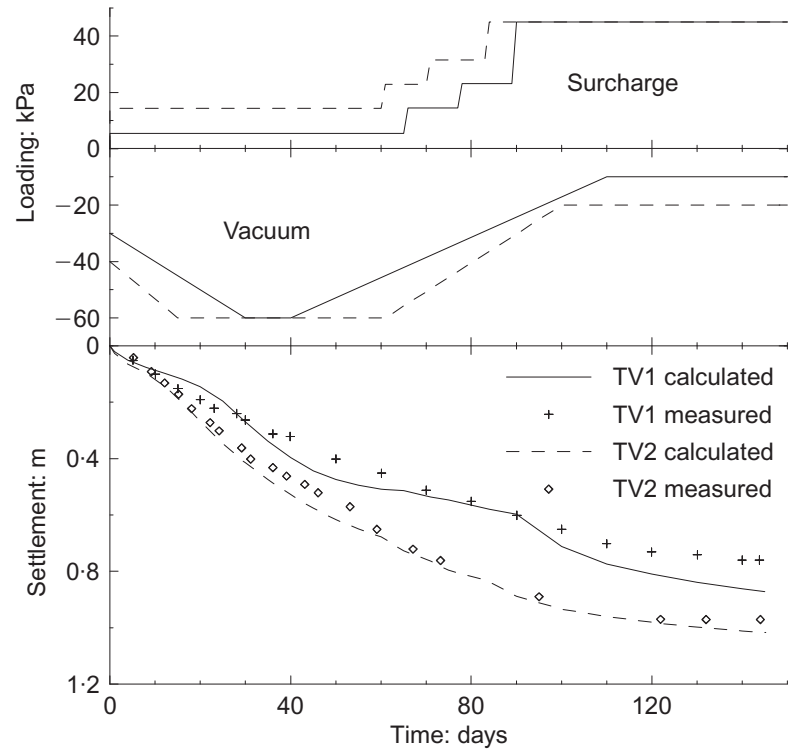

Fig. 7. Surface settlement plots for SBIA test embankments

loading sequences. A better match might be achieved if the assumed vacuum loading is corrected to account for air leaks, although it would be difficult to predict the actual loss of vacuum pressure in the field before construction.

Land subsidence owing to seasonal pumping of groundwater in Saga Plain, Japan

The Saga Plain on the Japanese island of Kyushu suffers from subsidence owing to seasonal changes in groundwater level. Groundwater pumping in summer for agriculture, and winter recharge causes changes in effective stress, resulting in consolidation. Sakai (2001) describes the monitoring of land subsidence in Saga Plain. The area is reclaimed from the Ariake Sea, consisting of $10-30 \mathrm{~m}$ of compressible marine clay underlain by a sandy aquifer. A series of observation wells was installed in the Shiroishi district in 1996 to investigate the changes in groundwater level and the associated subsidence settlements at various depths down to $90 \mathrm{~m}$ (Sakai, 2001). The changing groundwater level in one of the observation wells $(27.5 \mathrm{~m}$ depth $)$ is converted to excess pore water pressure and used with the proposed consolidation model to match the compression of the overlying $26 \mathrm{~m}$ of clay.

By using a dummy layer with high horizontal permeability at the bottom of the soil system, the changes in excess pore pressure caused by groundwater pumping can be simulated with the proposed consolidation model. An appropriate vacuum load is specified at this dummy layer, while not allowing horizontal drainage in the clay layer. The soil properties in the Shiroishi district are shown in Fig. 8. For pore pressure calculations, a single layer with uniform permeability and compressibility properties was used to model the $26 \mathrm{~m}$ of marine clay (the sandy aquifer below $26 \mathrm{~m}$ was not modelled). The groundwater level recorded at the $27.5 \mathrm{~m}$ deep observation well was converted to excess pore pressure values (see Fig. 9) and applied to the bottom of the clay by way of a dummy layer. To establish an initial pore pressure distribution, it was assumed that for 4 months prior to the start of observations, the applied modelled vacuum was equal to the first measured value of excess pore pressure. As for the Second Bangkok International Airport example, settlements are calculated after pore pressure values have been determined. The marine clay is divided into 30 sublayers (see Walker (2006) for full details), and the total settlement is found by summing the settlements of each

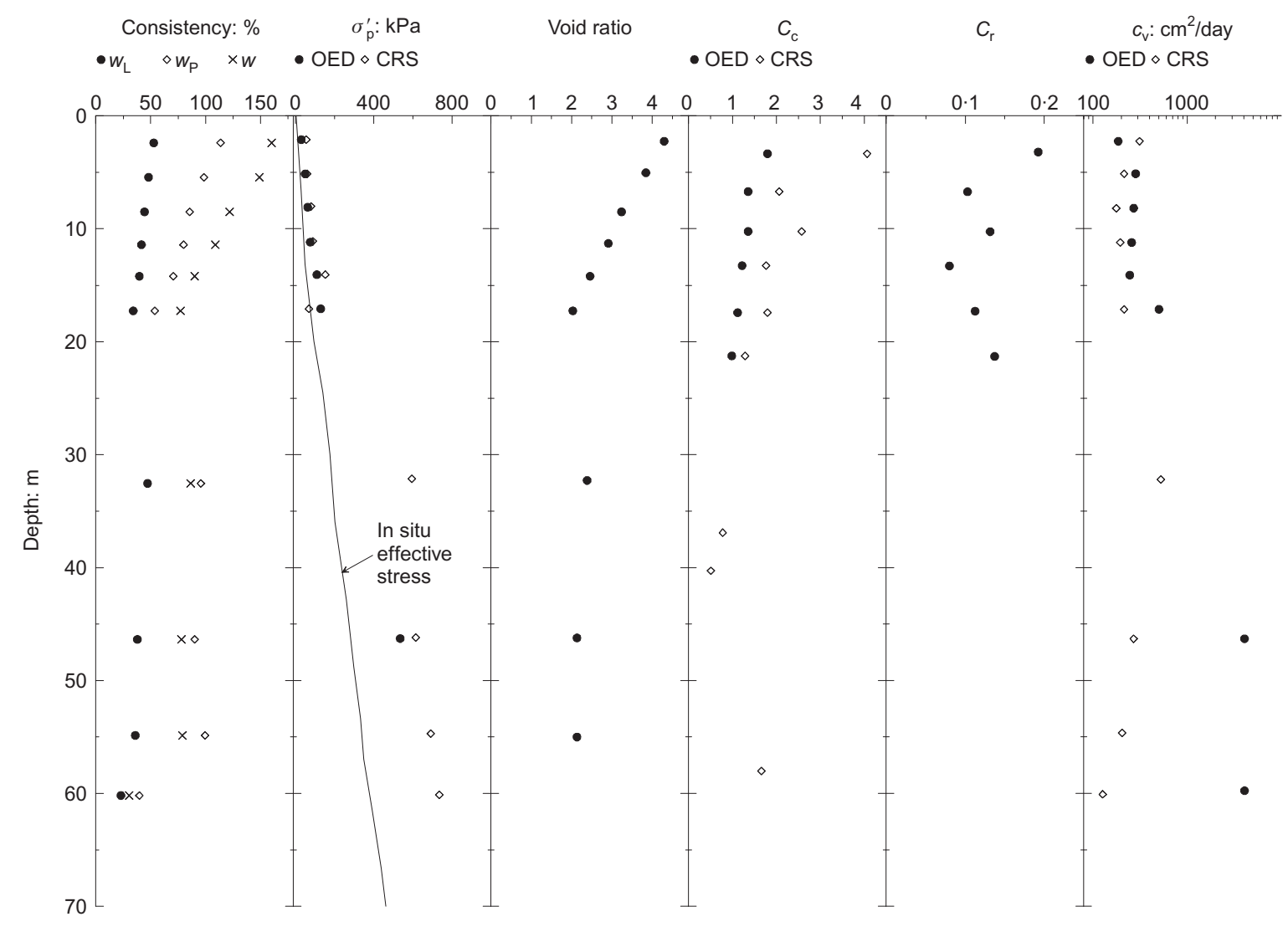

Fig. 8. Soil properties at Shiroisi (after Sakai, 2001) 


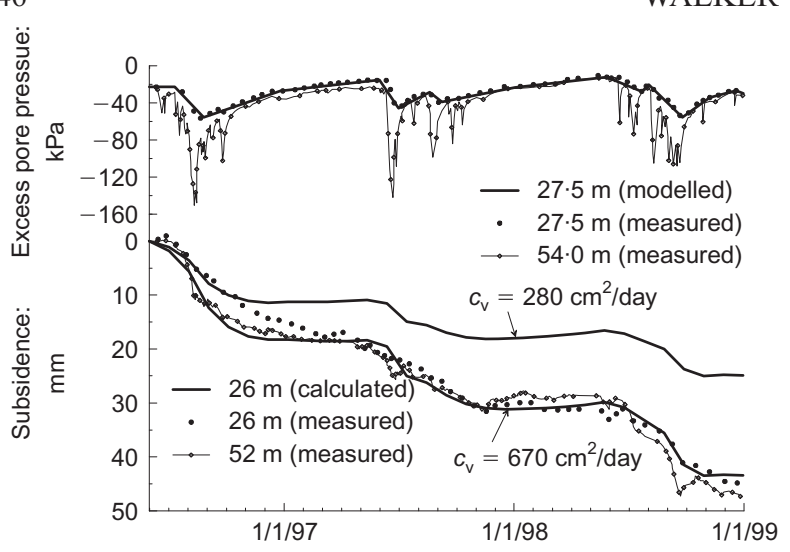

Fig. 9. Compression of marine clay

sublayer using equation (13). The relative settlement between the ground level and the observation well at $27.5 \mathrm{~m}$ depth is shown in Fig. 9 (20 series terms are used). Also shown are the measured pore pressure and settlement values in the $54 \mathrm{~m}$ deep observation well which is in the sandy aquifer. With a laboratory $c_{\mathrm{V}}$ value of $280 \mathrm{~cm}^{2} /$ day $\left(2 \times 10^{-8} \mathrm{~m}^{2} / \mathrm{s}\right)$, as shown in Fig. 8, the settlements are under-predicted. Clearly, a better match is found using $c_{\mathrm{V}}=670 \mathrm{~cm}^{2} /$ day $\left(5 \times 10^{-8} \mathrm{~m}^{2} / \mathrm{s}\right)$, which is about 2.4 times higher than the laboratory $c_{\mathrm{v}}$. In the field, it is not unusual to obtain values of $c_{\mathrm{V}}$ several factors larger than the values obtained for small laboratory specimens. Even though a higher $c_{\mathrm{V}}$ gives a better match there remains a discrepancy during the early months of analysis between the predicted and measured settlements of the top $26 \mathrm{~m}$ of clay. During this time the predicted settlements show a better match with those at $52 \mathrm{~m}$ depth. The otherwise good match between predicted and measured values suggests that in the initial stages movement occurs that is not reflected in the pore water measurements at $27.5 \mathrm{~m}$ depth. The discrepancy may also be owing to the largely unknown initial pore pressure distribution in the soil. Following this initial period, the calculated settlements match well with those measured. This example illustrates that consolidation caused by arbitrary changes in excess pore water pressure can be modelled with the proposed consolidation equations.

\section{CONCLUSION}

A new approach to analysing the pore pressure response of multi-layered soil systems has been presented. Based on equal-strain one-dimensional deformation theory, vertical and radial drainage is included. The powerful spectral method is used to solve the governing equation, producing a single expression, calculated with common matrix operations, to give the pore pressure profile across all soil layers. Accuracy is improved by increasing the number of terms in the series solution. With a single expression describing the pore pressure distribution calculating average pore pressure values within or across soil layers is far easier than with models where a separate equation is required for each layer. Combined vacuum and surcharge loading vary with both depth and time. No other analytical model includes vacuum loading of multiple soil layers. The spectral method allows for the novel treatment of multiple soil layers where permeability, compressibility, and vertical drain parameter vary in a linear fashion with depth in each layer. Owing to the linear variation, fewer layers are needed to model arbitrary spatial property distributions compared with existing analytical multi-layer analyses where properties are constant within a layer. By varying the vertical drain parameter $\eta$, multi-layer partially penetrating vertical drains or drain patterns with different length drains can be analysed.

The use of soil properties that vary in a linear fashion allows for, not only existing problems to be analysed but also new behaviour to be investigated. In this way 1D consolidation with constant coefficient of consolidation is found to vary with the variation of permeability and compressibility within the soil (see Fig. 3). This is significant for thick soil deposits with pervious top and impervious bottom drainage conditions. Ratios of top permeability to bottom permeability greater than one, $k_{\mathrm{vT}} / k_{\mathrm{vB}}>1$, lead to faster consolidation, and this is expected in the field.

The versatility and general nature of the spectral method model is demonstrated by accurate simulation of

(a) an existing multi-layered analytical model

(b) settlements from a large-scale consolidation cell under surcharge and vacuum loading

(c) surface settlements of two trial embankments of vacuum and surcharge loading at the Second Bangkok International Airport

(d) ground subsidence from groundwater pumping in the Saga Plain, Japan.

The case histories show that accurate prediction of pore water pressure dissipation and subsequent settlement calculation requires consideration of time- and depth-dependent surcharge and vacuum loading. The spectral method model presented herein can incorporate such loading changes, providing flexibility in analysis of multi-layered consolidation problems usually associated with purely numerical methods such as finite element analysis.

\section{APPENDIX: EXPLICIT MATRIX ELEMENT EXPRESSIONS}

This Appendix presents the matrix terms used in solution of the problem. General integral forms, valid for any distribution of soil properties and loading, are given and then solved for the piecewise linear distributions assumed in this paper. For brevity the normalising factor for material properties has been omitted. For example, $k_{\mathrm{v} l} l$ represents the value of $k_{\mathrm{v}} / \bar{k}_{\mathrm{v}}$ at normalised depth $Z_{l}$. This varies linearly to a value of $k_{\mathrm{v} l+1}$ at the bottom of the $l$ th layer. The vacuum and surcharge loads vary linearly with both depth and time such that at time $t_{m}$ the vacuum at the depth $Z_{l}$ is designated $w_{m, l}$. This varies linearly with time to $w_{m+1, l}$ at the end of the $m$ th loading stage (time $t_{m+1}$ ).

In performing the integrations in equations (10) and (11) many expressions of similar form arise. This is attributable to repeatedly integrating the product of trigonometric and linear polynomial functions. To present the equations for $\Gamma$, $\Psi, \sigma$, and $\mathbf{w}$ in a concise manner, a shorthand notation is adopted as described below

$$
\begin{aligned}
& S N\left[\alpha, \beta^{k}\right]=\frac{\alpha_{l+1} \sin \left(\beta Z_{l+1}\right)-\alpha_{l} \sin \left(\beta Z_{l}\right)}{\beta^{k}} \\
& C S\left[\alpha, \beta^{k}\right]=\frac{\alpha_{l+1} \cos \left(\beta Z_{l+1}\right)-\alpha_{l} \cos \left(\beta Z_{l}\right)}{\beta^{k}} \\
& M^{+}=M_{j}+M_{i} \\
& M^{-}=M_{j}-M_{i}
\end{aligned}
$$

and $\Delta$ is an operator in the $Z$ direction such that

$$
\Delta \alpha=\alpha_{l+1}-\alpha_{l}
$$

The $\boldsymbol{\Gamma}$ matrix depends solely on the compressibility of the soil. It is found by performing the integrations in equation (11) with the left-hand side of equation (1). Thus, the $l$ th soil layer's contribution to $\boldsymbol{\Gamma}_{i j}$ is 


$$
\Gamma_{i j}=\int_{Z_{l}}^{Z_{l+1}} \frac{m_{\mathrm{v}}}{\bar{m}_{\mathrm{v}}} \phi_{i} \phi_{j} \mathrm{~d} Z
$$

where $m_{\mathrm{v}} / \bar{m}_{\mathrm{v}}$ is a linear function of $Z$. Equation (19) gives different expressions for the diagonal $(i=j)$ and the off diagonal $(i \neq j)$ elements of $\boldsymbol{\Gamma}$. The diagonal elements are calculated with

$$
\begin{aligned}
\Gamma_{i j}= & \frac{1}{2}\left(\frac{\Delta Z}{2}\left(m_{\mathrm{v} l}+m_{\mathrm{v} l+1}\right)-\frac{\Delta m_{\mathrm{v}}}{\Delta Z}\right. \\
& \left.\times C S\left[1,\left(M^{+}\right)^{2}\right]-S N\left[m_{\mathrm{v}},\left(M^{+}\right)^{1}\right]\right), i=j
\end{aligned}
$$

The off diagonal elements are given by

$$
\begin{aligned}
\Gamma_{i j}= & \frac{1}{2}\left(\begin{array}{c}
\frac{\Delta m_{\mathrm{v}}}{\Delta Z}\left(C S\left[1,\left(M^{-}\right)^{2}\right]-C S\left[1,\left(M^{+}\right)^{2}\right]\right) \\
+S N\left[m_{\mathrm{v}},\left(M^{-}\right)^{1}\right]-S N\left[m_{\mathrm{v}},\left(M^{+}\right)^{1}\right]
\end{array}\right), \\
& i \neq j
\end{aligned}
$$

In interface layers, $Z_{l}=Z_{l+1}$, so the limit of equation (20) is taken as $Z_{l+1} \rightarrow Z_{l}$. This limit is zero for both diagonal and off diagonal elements.

The same approach used to find $\Gamma$ is also used to determine $\Psi$. The $\Psi$ matrix depends on the drainage properties of the soil (right-hand side of equation (1)). The $l$ th soil layer's contribution to $\Psi_{i j}$ is

$$
\begin{aligned}
\Psi_{i j}= & \int_{Z_{l}}^{Z_{l+1}} \mathrm{~d} T_{\mathrm{h}} \frac{\eta}{\bar{\eta}} \phi_{j} \phi_{i} \mathrm{~d} Z \\
& -\int_{Z_{l}}^{Z_{l+1}} \mathrm{~d} T_{\mathrm{v}}\left(\frac{\partial}{\partial Z}\left(\frac{k_{\mathrm{v}}}{\bar{k}_{\mathrm{v}}}\right) \phi_{j}^{\prime} \phi_{i}+\frac{k_{\mathrm{v}}}{\bar{k}_{\mathrm{v}}} \phi_{j}^{\prime \prime} \phi_{i}\right) \mathrm{d} Z
\end{aligned}
$$

where $\phi^{\prime}$ and $\phi^{\prime \prime}$ are the first and second derivatives of $\phi$. The contribution of vertical and horizontal drainage to the diagonal elements of $\Psi$ are given respectively by

$$
\begin{aligned}
& \Psi_{i j}=\frac{\mathrm{d} T_{\mathrm{v}} M_{j}^{2}}{2} \\
& \times\left(\frac{\Delta Z}{2}\left(k_{\mathrm{v} l}+k_{\mathrm{v} l+1}\right)+\frac{\Delta k_{\mathrm{v}}}{\Delta Z} C S\left[1,\left(M^{+}\right)^{2}\right]-S N\left[k_{\mathrm{v}},\left(M^{+}\right)^{1}\right]\right), \\
& i=j \\
& \Psi_{i j}=\frac{\mathrm{d} T_{\mathrm{h}}}{2} \\
& \times\left(\frac{\Delta Z}{2}\left(\eta_{l}+\eta_{l+1}\right)-\frac{\Delta \eta}{\Delta Z} C S\left[1,\left(M^{+}\right)^{2}\right]-S N\left[\eta,\left(M^{+}\right)^{1}\right]\right), \\
& i=j
\end{aligned}
$$

The off diagonal terms are

$$
\begin{aligned}
& \Psi_{i j}=\frac{\mathrm{d} T_{\mathrm{v}}}{2} \\
& \times\left(\begin{array}{c}
\frac{M_{j} M_{i} \Delta k_{\mathrm{v}}}{\Delta Z}\left(C S\left[1,\left(M^{-}\right)^{2}\right]+C S\left[1,\left(M^{+}\right)^{2}\right]\right) \\
+M_{j}^{2}\left(S N\left[k_{\mathrm{v}},\left(M^{-}\right)^{1}\right]-S N\left[k_{\mathrm{v}},\left(M^{+}\right)^{1}\right]\right)
\end{array}\right), \\
& i \neq j \\
& \Psi_{i j}=\frac{\mathrm{d} T_{\mathrm{h}}}{2}\left(\begin{array}{l}
\frac{\Delta \eta}{\Delta Z}\left(C S\left[1,\left(M^{-}\right)^{2}\right]-C S\left[1,\left(M^{+}\right)^{2}\right]\right) \\
+S N\left[\eta,\left(M^{-}\right)^{1}\right]-S N\left[\eta,\left(M^{+}\right)^{1}\right]
\end{array}\right) \\
& i \neq j
\end{aligned}
$$

For interface layers there is no contribution from horizontal drainage. The contribution of vertical drainage is the same for diagonal and off diagonal terms, and is described as

$$
\Psi_{i j}=-\mathrm{d} T_{\mathrm{v}} M_{j} \Delta k_{\mathrm{v}} \cos \left(M_{j} Z_{1}\right) \sin \left(M_{i} Z_{1}\right)
$$

The final values for $\Gamma$ and $\Psi$ are found by summing the contribution of each soil layer.

It is now possible to determine $\mathbf{E}$ and $\mathbf{v}$. The diagonal matrix $\mathbf{E}$ (square matrix with non-diagonal terms equal to zero) has diagonal elements

$$
E_{i i}=\exp \left[-\lambda_{i} t\right]
$$

where $\lambda_{i}$ are the $N$ eigenvalues of $\Gamma^{-1} \Psi$. $\mathbf{v}$ is the matrix of $N$ eigenvectors of $\Gamma^{-1} \Psi$.

The loading terms $\boldsymbol{\sigma}$ and $\mathbf{w}$ are found by considering equation (11). The surcharge loading term is defined by the following integral

$$
\sigma=\int_{0}^{\tau} \int_{0}^{1} \mathbf{E}(t-\tau)(\Gamma \mathbf{v})^{-1} \Phi(\zeta)^{T} \frac{m_{\mathrm{v}}}{\bar{m}_{v}} \frac{\partial \bar{\sigma}}{\partial t} \mathrm{~d} \zeta \mathrm{d} \tau
$$

The vacuum loading term is determined from

$$
\mathbf{w}=\int_{0}^{\tau} \int_{0}^{1} \mathbf{E}(t-\tau)(\Gamma \mathbf{v})^{-1} \Phi(\zeta)^{T} \mathrm{~d} T_{\mathrm{h}} \frac{\eta}{\bar{\eta}} w \mathrm{~d} \zeta \mathrm{d} \tau
$$

Performing the integrations in equations (25) and (26) for the $m$ th ramp load gives the $i$ th element of $\boldsymbol{\sigma}$ and $\mathbf{w}$ as

$$
\begin{aligned}
\sigma_{i}= & \frac{\Lambda_{1, m, i}}{t_{m+1}-t_{m}} \sum_{j=1}^{N}(\Gamma \mathbf{v})_{i j}^{-1} \\
& \times\left(\sum_{l=1}^{\# l} \Xi_{j}\left(\sigma_{m+1, l}-\sigma_{m, l}, \Delta \sigma_{m+1}-\Delta \sigma_{m}, m_{\mathrm{v}}\right)\right) \\
\mathbf{w}_{i}= & \left.\mathrm{d} T_{\mathrm{h}}\left(\begin{array}{c}
\Lambda_{1, m, i} \sum_{j=1}^{N}(\Gamma \mathbf{v})_{i j}^{-1}\left(\sum_{l=1}^{\# l} \Xi_{j}\left(w_{m, l}, \Delta w_{m}, \eta\right)\right) \\
+\frac{\Lambda_{2, m, i}}{t_{m+1}-t_{m}} \sum_{j=1}^{N}(\Gamma \mathbf{v})_{i j}^{-1} \\
\times\left(\sum_{l=1}^{\# l} \Xi_{j}\left(w_{m+1, l}-w_{m, l}, \Delta w_{m+1}-\Delta w_{m}, \eta\right)\right.
\end{array}\right)\right)
\end{aligned}
$$

where $\# l$ is the number of soil layers. $\Lambda$ and $\Xi$ are further shorthand notation defined by 


$$
\begin{aligned}
& \Xi_{j}(\alpha, \beta, \theta)=\frac{1}{M_{j}} \\
& \times\left(\begin{array}{l}
\alpha\left(\frac{\Delta \theta}{\Delta Z} S N\left[1, M_{j}^{1}\right]-C S\left[\theta, M_{j}^{0}\right]\right) \\
+\beta\left(\frac{2 \Delta \theta}{\Delta Z^{2}} C S\left[1, M_{j}^{2}\right]+\frac{1}{\Delta Z}\right. \\
\times\left(S N\left[\theta, M_{j}^{1}\right]+\frac{\Delta \theta}{M_{j}} \sin \left(M_{j} Z_{l+1}\right)\right) \\
\left.-\theta_{l+1} \cos \left(M_{j} Z_{l+1}\right)\right)
\end{array}\right) \\
& \Lambda_{\theta, m, i}=\left\{\begin{array}{l}
\frac{\exp \left[-t \lambda_{i}\right]\left(\exp \left[t_{\mathrm{f}} \lambda_{i}\right]-\exp \left[t_{\mathrm{s}} \lambda_{i}\right]\right)}{\lambda_{i}} \\
\frac{\exp \left[-t \lambda_{i}\right]\left(\left(1+\left(t_{\mathrm{m}}-t_{\mathrm{s}}\right) \lambda_{i}\right) \exp \left[t_{\mathrm{s}} \lambda_{i}\right]\right.}{\left.-\left(1+\left(t_{\mathrm{m}}-t_{\mathrm{f}}\right) \lambda_{i}\right) \exp \left[t_{\mathrm{f}} \lambda_{i}\right]\right)}
\end{array}\right. \\
& \lambda_{i}^{2}
\end{aligned}
$$$$
t_{\mathrm{s}}=\min \left[t, t_{1}\right]
$$$$
t_{\mathrm{f}}=\min \left[t, t_{2}\right]
$$

By formulating each ramp loading step with $t_{\mathrm{s}}$ and $t_{\mathrm{f}}$, it is not necessary to determine which is the current loading step, the formulation will make the contribution of loading steps that start after time $t$ equal to zero. For interface layers both $\boldsymbol{\sigma}$ and $\mathbf{w}$ are equal to zero. The start and end times of surcharge and vacuum loading stages need not be the same. The final values for $\boldsymbol{\sigma}$ and $\mathbf{w}$ are found by summing the contribution of each ramp load. For greatest computational efficiency only the $\Lambda$ functions in equation (30) need be computed at each time step. All other parameters depend only on material properties and loading magnitudes and can thus be initialised at the start of the analysis.

The average excess pore pressure between any two depths $Z_{l}$ and $Z_{l+1}$ is given by:

$$
\begin{aligned}
\overline{\bar{u}}(t) & =\int_{Z_{l}}^{Z_{l+1}} \Phi \mathbf{v}(\boldsymbol{\sigma}+\mathbf{w}) / \Delta Z \mathrm{~d} Z \\
& =\bar{\Phi} \mathbf{v}(\boldsymbol{\sigma}+\mathbf{w})
\end{aligned}
$$

where

$$
\bar{\Phi}=\left[\begin{array}{llll}
\bar{\phi}_{1} & \bar{\phi}_{2} & \ldots & \bar{\phi}_{N}
\end{array}\right]
$$

and

$$
\bar{\phi}=-\frac{1}{\Delta Z} C S\left(1, M^{1}\right)
$$

\section{REFERENCES}

Anderson, E., Bai, Z., Bischof, C.H., Blackford, S., Demmel, J., Dong-garra, J. J., Du Croz, J., Greenbaum, A., Hammarling, S., McKenney, A. \& Sorensen, D. C. (1999). LAPACK users' guide. Philadelphia: Society for Industrial and Applied Mathematics.

Asmar, N. H. (2004). Partial differential equations with Fourier series and boundary value problems. Upper Saddle River, NJ: Pearson Prentice Hall.

Barron, R. A. (1948). Consolidation of fine-grained soils by drain wells. Trans. ASCE 113, 718-742.
Bergado, D. T., Anderson, L. R., Miura, N. \& Balasubramaniam, A. S. (1996). Soft ground improvement in lowland and other environments. Reston, Virginia: American Society of Civil Engineers.

Bergado, D. T., Chai, J. C., Miura, N. \& Balasubramaniam A. S. (1998). PVD improvement of soft Bangkok clay with combined vacuum and reduced sand embankment preloading. Geotech. Engng J., Southeast Asian Geotech. Soc. 29, No. 1, 95-122.

Boyd, J. (2000). Chebyshev and Fourier spectral methods. New York: Dover Publications.

Chen, R.P., Zhou, W. H., Wang, H. Z. \& Chen, Y. M. (2005). Onedimensional nonlinear consolidation of multi-layered soil by differential quadrature method. Comput. Geotech. 32, No. 5, $358-369$.

Craig, R. F. (1997). Soil mechanics. London: E \& FN Spon.

Duncan, J. M. (1993). Limitations of conventional analysis of consolidation settlement. J. Geotech. Engng Div. ASCE 119, No. 9, 1333-1359.

Han, J. \& Ye, S. L. (2002). A theoretical solution for consolidation rates of stone column-reinforced foundations accounting for smear and well resistance effects. Int. J. Geomech. 2, No. 2, $135-151$.

Hansbo, S. (1981). Consolidation of fine-grained soils by prefabricated drains. Proc. 10th Int. Conf. Soil Mech. Foundation Engng, Stockholm 3, 677-682.

Hansbo, S. (2001). Consolidation equation valid for both Darcian and non-Darcian flow. Geotechnique 51, No. 1, 51-54.

Hird, C. C., Pyrah I. C. \& Russell, D (1992). Finite element modelling of vertical drains beneath embankments on soft ground. Geotechnique 42, No. 3, 499-511.

Hoffman, J. D. (1992). Numerical methods for engineers and scientists. New York: McGraw-Hill

Horne, M. R. (1964). The consolidation of a stratified soil with vertical and horizontal drainage. Int. J. Mech. Sci. 6, No. 2, $187-197$.

Indraratna, B., Balasubramaniam, A. S. \& Sivaneswaran, N. (1997). Analysis of settlement and lateral deformation of soft clay foundation beneath two full-scale embankments. Int. J. Numer Anal. Methods Geomech. 21, No. 9, 599-618.

Indraratna, B., Bamunawita, C. \& Khabbaz, H. (2004). Numerical modeling of vacuum preloading and field applications. Can. Geotech. J. 41, No. 6, 1098-1110.

Indraratna, B. \& Redana, I. W. (1998a). Laboratory determination of smear zone due to vertical drain installation. J. Geotech. Geoenviron. Engng, ASCE 124, No. 2, 180-185.

Indraratna, B. \& Redana, I. W. (1998b). Development of the smear zone around vertical band drains. Ground Improvement 2, No. 4, $180-185$.

Indraratna, B. \& Redana I. W. (2000). Numerical modeling of vertical drains with smear and well resistance installed in soft clay. Can. Geotech. J. 37, No. 1, 132-145.

Indraratna, B., Sathananthan, I., Rujikiatkamjorn, C. \& Balasubramaniam, A. S. (2005). Analytical and numerical modeling of soft soil stabilized by prefabricated vertical drains incorporating vacuum preloading. Int. J. Geomech. 5, No. 2, 114-124.

Leo, C. J. (2004). Equal strain consolidation by vertical drains. $J$. Geotech. Geoenviron. Engng ASCE 130, No. 3, 316-327.

Nogami, T. \& Li, M. (2002). Consolidation of system of clay and thin sand layers. Soil Found., Jap. Geotech Soc. 42, No. 4, 111.

Nogami, T. \& Li, M. (2003). Consolidation of clay with a system of vertical and horizontal drains. J. Geotech. Geoenviron. Engng, ASCE 129, No. 9, 838-848.

Rixner, J. J., Kraemer, S. R., \& Smith, A. D. (1986). Prefabricated Vertical Drains, Vol. I, II and III: Summary of Research ReportFinal Report, FHWA-RD-86/169, Washington D.C.

Sakai, A. (2001). Land subsidence due to seasonal pumping of groundwater in Saga Plain, Japan. Lowland Technol. Int. 3, No. $1,25-40$.

Sathananthan, I \& Indraratna, B. (2006). Laboratory evaluation of smear zone and correlation between permeability and moisture content. J. Geotech. Geoenviron. Engng 132, No. 7, 942.

Schiffman, R. L. \& Stein J. R. (1970). One-dimensional consolidation of layered systems. J. Soil Mech. Found. Engng, ASCE 96, No. 4, 1499-1504.

Tang, X. W. \& K. Onitsuka, K. (2000). Consolidation by vertical 
drains under time-dependent loading. Int. J. Numer. Anal. Methods Geomech. 24, No. 9, 739-751.

Tang, X. W. \& Onitsuka, K. (2001). Consolidation of doublelayered ground with vertical drains. Int. J. Numer. Anal. Methods Geomech. 25, No. 14, 1449-1465.

Terzaghi, K. (1943). Theoretical soil mechanics. New York: John Wiley.

Volpi, L. (2005). MATRIX: Matrix and Linear Algebra addin for EXCEL. Piombini, Italy: Foxes Team.

Walker, R. (2006). Analytical solutions for modeling soft soil consolidation by vertical drains. $\mathrm{PhD}$ thesis, University of Wollongong, NSW, Australia.

Walker, R. \& Indraratna, B. (2006). Vertical drain consolidation with parabolic distribution of permeability in smear zone. J. Geotech. Geoenviron. Engng, ASCE 132, No. 7, 937-941.

Walker, R. \& Indraratna, B. (2007). Vertical drain consolidation with overlapping smear zones. Geotechnique 57, No. 5, 463-467.
Wang, X.-S. \& Jiao, J. J. (2004). Analysis of soil consolidation by vertical drains with double porosity model. Int. J. Numer. Anal. Methods Geomech. 28, No. 14, 1385-1400.

Xie, K.-H., Xie, X.-Y. \& Gao, X. (1999). Theory of one dimensional consolidation of two-layered soil with partially drained boundaries. Comput. Geotech. 24, No. 4, 265-278.

Xie, K.-H., Xie, X.-Y. \& Jiang, W. (2002). A study on onedimensional nonlinear consolidation of double-layered soil. Comput. Geotech. 29, 151-168.

Yoshikuni, H. \& Nakanodo, H. (1974). Consolidation of finegrained soils by drain wells with finite permeability. Soil Found. Jap. Geotech. Soc. 14, No. 2, 35-46.

Zhu, G. \& Yin, J.-H. (2005). Solution charts for the consolidation of double soil layers. Can. Geotech. J. 42, 949-956.

Zhu, G. \& Yin, J. H. (2001). Consolidation of soil with vertical and horizontal drainage under ramp load. Geotechnique 51, No. 4, 361-367. 